\title{
A Rapid New Approach for the Quality Evaluation of the Folk Medicine Dianbaizhu Based on Chemometrics
}

\author{
Zizhen Liu, ${ }^{a}$ Rui Jiang, ${ }^{a}$ Meng Xie, ${ }^{a}$ Guanling Xu, ${ }^{a}$ Weirui Liu, ${ }^{a}$ Xiaohong Wang, ${ }^{a}$ \\ Hongying Lin, ${ }^{a}$ Jianqiu Lu, ${ }^{*, b}$ and Gaimei She ${ }^{*, a}$ \\ ${ }^{a}$ School of Chinese Pharmacy, Beijing University of Chinese Medicine; Beijing 100102, China: and ${ }^{b}$ Science \\ Experiment Center for Traditional Chinese Medicine, Beijing University of Chinese Medicine; Beijing 100029, China. \\ Received May 30, 2014; accepted August 12, 2014
}

\begin{abstract}
Dianbaizhu, a folk medicine from Gaultheria leucocarpa Blume var. yunnanensis (Franch.) T. Z. Hsu \& R. C. FANG (Ericaceae) used as an antirheumatic, has multiple plant origins and officinal parts. A rapid highperformance liquid chromatography with diode array detector (HPLC-DAD) method was established for the simultaneous determination of the characteristic ingredient methyl benzoate-2- $O$ - $\beta$-D-glucopyranosyl $(1 \rightarrow 2)$ $[O$ - $\beta$-D-xylopyranosyl $(1 \rightarrow 6)]-O$ - $\beta$-D-glucopyranoside and seven bioactive constituents in eight Gaultheria species. This chromatographic method is precise, accurate, and stable. Kruskal-Wallis analysis, hierarchical cluster analysis, and factor analysis were used to analyze the content of reference compounds in different Gaultheria species and officinal parts. The analyses showed significant differences $(p<0.05)$ in Gaultheria species but few differences $(p>0.05)$ in their medicinal parts. G. leucocarpa var. yunnanensis appeared to the best among the Gaultheria species tested for the treatment of rheumatic diseases. Taken together, the results show that this simultaneous quantification of multiple active constituents using HPLC-DAD combined with chemometrics can be reliably applied to evaluate the quality of Dianbaizhu.
\end{abstract}

Key words Dianbaizhu; Chinese folk medicine; quality evaluation; chemometrics; HPLC coupled with diode array detector

Dianbaizhu, the whole plant or root or aerial part of Gaultheria leucocarpa Blume var. yunnanensis (FrANCH.) T. Z. Hsu \& R. C. FANG (Ericaceae), is widely used for the treatment of rheumatic disease by ethnic minority people. ${ }^{1)}$ Some other plants of Gaultheria genus, Gaultheria fragrantissima, Gaultheria leucocarpa var. pingbienensis, and Gaultheria griffithiana, are also regarded as Dianbaizhu by many minority nationalities to treat rheumatism in clinical practice. ${ }^{1,2)}$ The whole plant of the above-mentioned species is used as Dianbaizhu in the Bai ethnic minority. The aerial part is deemed to be Dianbaizhu in the other minority nationalities. ${ }^{2-4)}$ In addition, the leaves of G. fragrantissima are sold as Dianbaizhu in Chuxiong medicine market.

The G. leucocarpa var. yunnanensis is a research focus in the genus Gaultheria. Our project team and others reported salicylic acid derivatives, flavonoids, terpenoids, lignins and organic acids were the primary ingredients of this plant. ${ }^{1,2,5}$ Methyl benzoate-2- $O-\beta$-D-glucopyranosyl $(1 \rightarrow 2)-[O-\beta$-D-xylopyranosyl $(1 \rightarrow 6)]-O-\beta$-D-glucopyranoside (MSTG-B), together with salicylic acid and methyl salicylate with favorable antiinflammatory activities were confirmed as non-steroid antiinflammation drugs (NSAIDs) ${ }^{6-8)}$ Futhermore, the quercitrin, ${ }^{9,10)}$ hyperoside, ${ }^{11)}$ cynaroside, ${ }^{12)}$ chlorogenic acid ${ }^{12-14)}$ and vanillic $\operatorname{acid}^{15)}$ in $G$. leucocarpa var. yunnanensis, possess reducing the inflammation abilities. Our group current study also supported that the above-mentioned compounds were principle anti-rheumatic constituents by anti-rheumatism fingerprint-efficacy relationship on the basis of $G$. leucocarpa var. yunnanensis.

To the best of our knowledge, now, the evaluation to the quality of genus Gaultheria always takes one or a type of index ingredient without anti-inflammatory effect as the standard compound. ${ }^{16-20)}$ And it is just only concentrated on the

The authors declare no conflict of interest. whole plant of G. leucocarpa var. yunnanensis. ${ }^{21-23)}$ Here, a new approach was established to evaluate the quality on $G$. leucocarpa var. yunnanensis with multiple active constituents prepared by our group as index compounds. And it can be used for some other species in Gaultheria together with various officinal parts. So to sum up, by using the established method and several chemometric methods, the medicinal plant resources of Dianbaizhu were assessed well.

\section{Experimental}

Herb Materials Thirty-six Dianbaizhu samples from eight species, collected in different producing areas in Yunnan province of China were authenticated by Dr. Shengli Wei, School of Beijing University of Chinese Medicine, Beijing (shown in Table 1).

Instrumentation and Reagents A Waters HPLC system consisting of a quaternary HPLC pump (Waters Model 2695), an auto injector (Waters 2695 separation module), a $100 \mu \mathrm{L}$ loop, a Waters 2695 column oven and a photodiode array detector (Waters 2998) were employed with a data system (Empower-2) in this study. An ultrasonic cleaner (KQ-250DE, Kunshan, Jiangsu, China) was used for extraction. Water for HPLC was purified by a Millipore Synergy UV system $(18.2 \mathrm{M} \Omega \mathrm{cm}$, Billerica, MA, U.S.A.), and then used for all the solutions and dilutions. HPLC grade acetonitrile (ACN) and methanol $(\mathrm{MeOH})$ of Fisher Scientific (Fairlawn, NJ, U.S.A.), together with chromatographic grade acetic acid and phosphoric acid from Beijing Chemical Works (Beijing, China) were employed.

The $70 \%$ ethanol extract of G. trichoclada was chromatographed on silica gel column, AB-8, MCI-gel CHP20P and ODS-A to give chlorogenic acid (1), vanillic acid (2), MSTG-B (3), hyperoside (4), cynaroside (5), salicylic acid (6), quercitrin (7) and methyl salicylate (8), respectively. And their purity all reached more than $98 \%$. They were used as index compounds 
Table 1. The Samples Information

\begin{tabular}{|c|c|c|c|c|}
\hline Batches & Species & Sample source & Harvesting time & Medicinal parts ${ }^{a}$ \\
\hline A & G. trichoclada & Chuxiong, Yunnan & June 2011 & $a, c, d$ \\
\hline $\mathrm{B}$ & G. semi-infera & Dali, Yunnan & August 2011 & $a, b, c, d$ \\
\hline $\mathrm{C}$ & G. griffithiana & Baoshan, Yunnan & December 2011 & $a, c, d$ \\
\hline $\mathrm{D}$ & G. leucocarpa var. yunnanensis & Dali, Yunnan & December 2011 & $a, c, d$ \\
\hline $\mathrm{E}$ & G. leucocarpa var. hirsuta & Baoshan, Yunnan & December 2011 & $a, b, c, d$ \\
\hline $\mathrm{F}$ & G. hookeri & Baoshan, Yunnan & December 2011 & $a, b, c, d$ \\
\hline G & G. leucocarpa var. pingbienensis & Qujin, Yunnan & August 2012 & $a, b, c, d$ \\
\hline $\mathrm{H}$ & G. fragrantissima & Dali, Yunnan & August 2012 & $a, b, c, d$ \\
\hline I & G. fragrantissima & Dali, Yunnan & October 2012 & $a, b, c, d$ \\
\hline $\mathrm{J}$ & G. fragrantissima & Dali, Yunnan & December 2012 & $a, b, d$ \\
\hline
\end{tabular}

a) $a$ : Aerial parts, $b$ : Whole plant, $c$ : Leaf, $d$ : Branch.<smiles>O=C(/C=C/c1ccc(O)c(O)c1)O[C@H]1C[C@@](O)(C(=O)O)C[C@H](O)[C@H]1O</smiles>

Chlorogenic acid (1)<smiles>COc1ccc(C(=O)O)c(O)c1</smiles>

Vanillic acid (2)

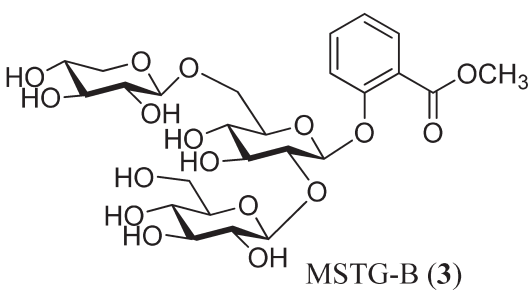

MSTG-B (3)<smiles>O=c1c(OC2OC(O)C(O)C(O)C2O)c(-c2ccc(O)c(O)c2)oc2cc(O)cc(O)c12</smiles>

Hyperoside (4)<smiles>CC1C(O)C(O)C(O)C(O)C1Oc1c(-c2ccc(O)c(O)c2)oc2cc(O)cc(O)c2c1=O</smiles><smiles>O=c1cc(-c2ccc(O)c(O)c2)oc2cc(OC3OC(O)C4COCC3C(O)C4)cc(O)c12</smiles>

Cynaroside (5)<smiles>O=C(O)c1ccccc1O</smiles>

Salicylic acid (6)<smiles>COC(=O)c1ccccc1O</smiles>

Methyl salicylate (8)

Fig. 1. Structures of the Eight Active Ingredients

in this study and their chemical structures were shown in Fig. 1.

Preparations of Sample and Standard Solution All the dried samples of Dianbaizhu were crushed into powder in a grinder, and then passed through a 20 -mesh sieve. Accurately weigh $1.0 \mathrm{~g}$ powder, in $20 \mathrm{~mL}$ ethanol-water $(1: 1, \mathrm{v} / \mathrm{v})$, extract by dint of sonication (power: $250 \mathrm{~W}$, frequency: $99 \mathrm{kHz}$ ) at $25^{\circ} \mathrm{C}$ for $60 \mathrm{~min}$. Then the extract was replenished to $20 \mathrm{~mL}$ with extraction solvent, shook well and filtered with a syringe filter $(0.22 \mu \mathrm{m}$, Alltech, Beerfield, IL, U.S.A.) prior to injecting an aliquot of $10 \mu \mathrm{L}$ solution into the HPLC system.

Standards (1-8) were weighed accurately and dissolved in ethanol-water $(1: 1, \mathrm{v} / \mathrm{v})$ to prepare the stock solutions at the concentrations of $214,192,230,510,204,250,202$ and $204 \mu \mathrm{g} / \mathrm{mL}$, respectively. The stock solution was appropriately diluted with ethanol-water $(1: 1, \mathrm{v} / \mathrm{v})$ to obtain series of working standard solutions. All solutions were filtered through $0.22 \mu \mathrm{m}$ membrane filter before HPLC analysis.
HPLC and Data Analysis All separations were carried out on a Thermo Hypersil Gold $\mathrm{C}_{18}$ column $(150 \mathrm{~mm} \times 4.6 \mathrm{~mm}$, $5 \mu \mathrm{m}$ ) by HPLC system (Waters 2695 ) with diode array detection (DAD). The optimum detection wavelength was set at $290 \mathrm{~nm}$ according to the result of wavelength scanning from 200 to $400 \mathrm{~nm}$. The mobile phase comprised $0.5 \%$ acetic acid in water (solvent A) and acetonitrile (solvent B). A linear gradient elution was performed as follow: $0-12 \mathrm{~min}, 10 \%$ B; $12-25 \mathrm{~min}, 10-20 \% \mathrm{~B} ; 25-40 \mathrm{~min}, 20 \% \mathrm{~B} ; 40-50 \mathrm{~min}$, $20-60 \% \mathrm{~B} ; 50-55 \mathrm{~min}, 60-75 \% \mathrm{~B}$. The flow rate was $1.0 \mathrm{~mL} /$ min and the injection volume was $10 \mu \mathrm{L}$.

In this study, all the data analyses were performed by the SPSS 20.0 (SPSS Science, Chicago, IL, U.S.A.).

\section{Results and Discussion}

Sample Analysis Based on Medical Statistics The whole plant or the aerial-part of some Gaultheria species is used as Dianbaizhu in several minority nationalities. ${ }^{24,25)}$ And some 
Table 2. Content of Eight Compounds (mg/g, $n=3$ )

\begin{tabular}{|c|c|c|c|c|c|c|c|c|}
\hline \multirow{2}{*}{ Samples } & \multicolumn{8}{|c|}{ Active ingredients } \\
\hline & 1 & 2 & 3 & 4 & 5 & 6 & 7 & 8 \\
\hline $\mathrm{A} a$ & 0.23 & 0.04 & 0.07 & 21.19 & 0.03 & 0.78 & 0.24 & 1.26 \\
\hline $\mathrm{Ac}$ & 0.13 & 0.05 & 0.05 & 9.17 & - & 0.43 & 0.16 & 2.12 \\
\hline $\mathrm{A} d$ & 0.44 & 0.04 & 0.07 & 44.76 & 0.11 & 0.56 & 0.47 & 3.94 \\
\hline $\mathrm{B} a$ & 0.20 & 0.06 & - & 1.87 & 0.15 & 0.06 & 0.35 & 1.14 \\
\hline $\mathrm{B} b$ & 0.29 & 0.03 & - & 2.05 & 0.10 & 0.19 & 0.23 & 1.41 \\
\hline $\mathrm{B} c$ & 0.21 & 0.02 & 0.08 & 1.04 & 0.04 & 0.10 & 0.04 & 1.52 \\
\hline $\mathrm{B} d$ & 0.97 & 0.03 & - & 4.00 & 4.39 & 0.44 & 0.22 & 2.63 \\
\hline $\mathrm{C} a$ & 2.39 & 0.05 & 0.05 & 2.37 & 2.00 & 0.19 & 6.64 & 1.01 \\
\hline $\mathrm{C} c$ & 3.13 & 0.03 & - & 0.73 & 0.40 & 0.47 & 0.56 & 1.24 \\
\hline $\mathrm{Cd}$ & 0.77 & 0.03 & - & 1.20 & 0.06 & 0.09 & 0.16 & 0.16 \\
\hline $\mathrm{D} a$ & 11.19 & 0.10 & 0.05 & 341.99 & 0.98 & 1.00 & 5.07 & 0.13 \\
\hline $\mathrm{D} c$ & 9.11 & 0.11 & 0.72 & 253.33 & 0.24 & 0.77 & 2.19 & 0.05 \\
\hline $\mathrm{D} d$ & 17.14 & 0.70 & - & 356.73 & 2.83 & 3.79 & 14.34 & 0.06 \\
\hline $\mathrm{E} a$ & 0.49 & 0.09 & 0.17 & 46.15 & 0.06 & 0.29 & 1.01 & 0.24 \\
\hline $\mathrm{E} b$ & 0.38 & 0.02 & 0.27 & 14.22 & - & 0.13 & 0.43 & 0.48 \\
\hline $\mathrm{E} c$ & 0.08 & 0.05 & 0.06 & 6.99 & 0.01 & 0.18 & 0.45 & 1.62 \\
\hline $\mathrm{E} d$ & 3.33 & 0.04 & 0.08 & 131.32 & 0.05 & 0.49 & 3.49 & 0.94 \\
\hline $\mathrm{F} a$ & 0.2 & 0.04 & - & 14.56 & - & 0.15 & 0.10 & 1.59 \\
\hline $\mathrm{F} b$ & 0.29 & 0.05 & 0.28 & 35.60 & 0.09 & 0.26 & 0.13 & 2.38 \\
\hline $\mathrm{F} c$ & 0.06 & 0.03 & - & 9.89 & - & 0.16 & 0.09 & 3.18 \\
\hline $\mathrm{F} d$ & 1.31 & 0.11 & - & 31.34 & 0.45 & 0.35 & 0.09 & 2.59 \\
\hline $\mathrm{G} a$ & 0.18 & 0.06 & 0.09 & 12.32 & 0.01 & 0.27 & 0.38 & 1.15 \\
\hline $\mathrm{G} b$ & 0.18 & 0.06 & 0.1 & 11.44 & 0.03 & 0.31 & 0.35 & 1.21 \\
\hline $\mathrm{Gc}$ & 0.05 & 0.05 & 0.12 & 0.60 & - & 0.14 & 0.01 & 1.01 \\
\hline $\mathrm{G} d$ & 0.82 & 0.07 & 0.07 & 71.62 & - & 0.41 & 1.96 & 0.61 \\
\hline $\mathrm{H} a$ & 0.28 & 0.04 & 0.05 & 15.44 & 0.01 & 0.15 & 0.21 & 3.42 \\
\hline $\mathrm{H} b$ & 0.22 & 0.03 & - & 3.88 & 0.27 & 0.14 & 0.37 & 1.68 \\
\hline $\mathrm{H} c$ & 0.11 & - & - & - & 0.12 & 0.28 & - & 1.68 \\
\hline $\mathrm{H} d$ & 0.10 & 0.03 & - & - & 1.48 & 0.17 & 0.27 & 0.63 \\
\hline $\mathrm{I} a$ & 0.54 & - & 0.01 & 0.43 & 0.48 & 0.14 & 0.04 & 5.14 \\
\hline $\mathrm{I} b$ & 0.23 & - & 0.03 & 3.23 & 0.59 & - & 0.18 & 2.44 \\
\hline $\mathrm{I} c$ & 0.15 & 0.02 & 0.02 & 0.16 & 0.01 & - & 0.01 & 3.00 \\
\hline $\mathrm{I} d$ & 0.16 & 0.03 & 0.02 & 3.59 & 0.44 & - & 0.39 & 10.52 \\
\hline $\mathrm{J} a$ & 0.31 & 0.02 & - & 8.33 & 0.28 & 0.08 & 0.08 & 3.57 \\
\hline $\mathrm{J} b$ & 0.30 & - & - & 0.47 & 1.12 & 0.15 & 0.08 & 3.60 \\
\hline $\mathrm{J} d$ & 0.78 & 0.02 & - & 3.58 & 0.50 & 0.10 & 0.30 & 8.67 \\
\hline
\end{tabular}

-: Below the LOD.

southern ethnic minorities directly use the leaves and branches as internal or external medicine for expelling wind-damp. ${ }^{4,24}$ Here, our investigated subjects included 10 batches of 36 samples, which consisted of the aerial-part $(a)$, whole plant $(b)$, leaf-part $(c)$ and branch-part $(d)$ of Dianbaizhu (Table 1). The content of eight active ingredients in all samples was shown in Table 2. Obviously, there was a wide variance at the content of all analytes in the 10 batches. It was due to various kinds of factors, such as plant origins, geographical conditions, climates, and some other hidden factors.

Optimization of Extraction Conditions To obtain the largest quality of the chemical constituents from Dianbaizhu, two extraction methods were tried, ultrasonic extraction (setting temperature: $25^{\circ} \mathrm{C}$ ) and heating reflux extraction. The former method was slightly better than the latter. Thus, ultrasonic extraction was chosen and the extraction optimization was executed. Three main extraction factors of the ultrasonic extraction were optimized through a $\mathrm{L}_{9}\left(3^{3}\right)$ orthogonal experiment. Table 3 demonstrated the factors and levels of the or- thogonal experiment. The sum of peaks area of eight analytes (1-8) was chosen as the norm to assess the optimal extraction condition. Three factors affected extraction ability were in the order: $\mathrm{B}>\mathrm{A}>\mathrm{C}$, according to the range analysis of the orthogonal experiment (Table 3). Consequently, the optimal extraction condition was that $1.0 \mathrm{~g}$ powder of dried sample extracted once with $20 \mathrm{~mL} 50 \%$ ethanol by ultrasonic extraction for $60 \mathrm{~min}$.

Optimization of HPLC Conditions In this section, the main chromatographic optimization program included selecting the composition and gradient of mobile phase, column temperature as well as detection wavelength. Several mobile phases, including $\mathrm{MeOH}-$ water, $\mathrm{ACN}$-water, $\mathrm{ACN}-0.1 \%$ phosphoric acid, ACN-0.5\% acetic acid and $\mathrm{ACN}-1.0 \%$ acetic acid were screened. Finally, ACN $-0.5 \%$ acetic acid was regarded as the optimal mobile phase, for it giving better separation and lower column pressure. The most appropriate temperature was set at $30^{\circ} \mathrm{C}$. The following two points were thought out, (i) the maximum UV absorption wavelengths 
Table 3. The Orthogonal Design of Extraction Conditions

\begin{tabular}{|c|c|c|c|c|}
\hline Run no. & $\mathrm{A}^{a)}$ & $\mathrm{B}^{b)}$ & $\mathrm{C}^{c)}$ & $A_{\Sigma}{ }^{d)}$ \\
\hline 1 & 20 & 30 & 30 & 1476791 \\
\hline 2 & 20 & 50 & 60 & 1768716 \\
\hline 3 & 20 & 70 & 90 & 1430540 \\
\hline 4 & 40 & 30 & 90 & 1323386 \\
\hline 5 & 40 & 50 & 30 & 1514868 \\
\hline 6 & 40 & 70 & 60 & 1523278 \\
\hline 7 & 60 & 30 & 60 & 1448059 \\
\hline 8 & 60 & 50 & 90 & 1591427 \\
\hline 9 & 60 & 70 & 30 & 1576916 \\
\hline$K_{1}^{e)}$ & 4676047 & 4248236 & 4591496 & \\
\hline$K_{2}$ & 4361532 & 4875011 & 4669018 & \\
\hline$K_{3}$ & 4616402 & 4530734 & 4393467 & \\
\hline$k_{1}^{f)}$ & 1558682 & 1416078 & 1530498 & \\
\hline$k_{2}$ & 1453844 & 1625003 & 1556339 & \\
\hline$k_{3}$ & 1538800 & 1510244 & 1464489 & \\
\hline Range & 104838 & 208925 & 91850 & \\
\hline Optimized scheme & A1 & B2 & $\mathrm{C} 2$ & \\
\hline Primary and secondary order & 2 & 1 & 3 & \\
\hline
\end{tabular}

a) A: Solvent volume (mL). b) B: Ethanol concentration (\%). c) C: Sonication time (min). d) $A_{\Sigma}$ : The area sum of 8 peaks (from analytes 1 to 8 ). e) $K$ : The total value of the same level of the same factor. $f$ ) $k$ : The average value of the same level of the same factor. of compounds (1-8) being 326, 220, 289, 350, 255, 204, 256 and $290 \mathrm{~nm}$, respectively, and (ii) the strong UV absorption of ACN presents approximately $210 \mathrm{~nm}$. Then, the $290 \mathrm{~nm}$ was found to be optimal, since the eight analytes revealed adequate absorptions. The favorable separation of eight mixed standards presented within 55 min under the optimal HPLC chromatograms conditions, as well as that of the samples (Fig. 2). Eight peaks in the chromatogram of the tested samples were corresponded with those of the eight standards under the same conditions, and eight standards were identified in the tested samples. In addition, the standard-addition method was also a way to confirm the peaks of analytes.

Method Validation The stock solutions containing eight components were further diluted to five appropriate concentration levels. The each calibration curve was established with six series concentration injected in triplicate, and plotted on the basis of the corresponding relation between peak area and concentration. For all analytes, good linearities $(r>0.9998)$ were achieved within the wide concentration range. The results of linear regression were given in Table 4.

As the standard stock solutions continuously diluted, the limit of detection (LOD) and the limit of quantity (LOQ) of the eight components could be determined respectively, when

(A)

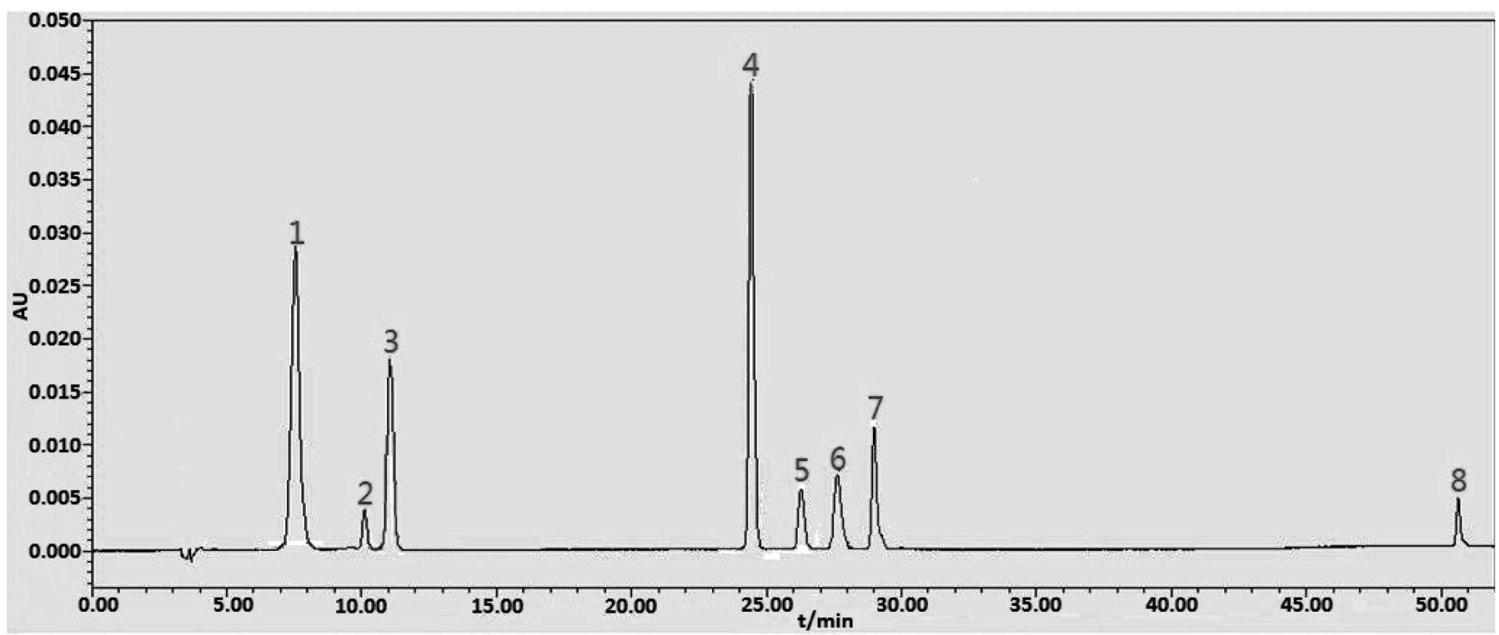

(B)
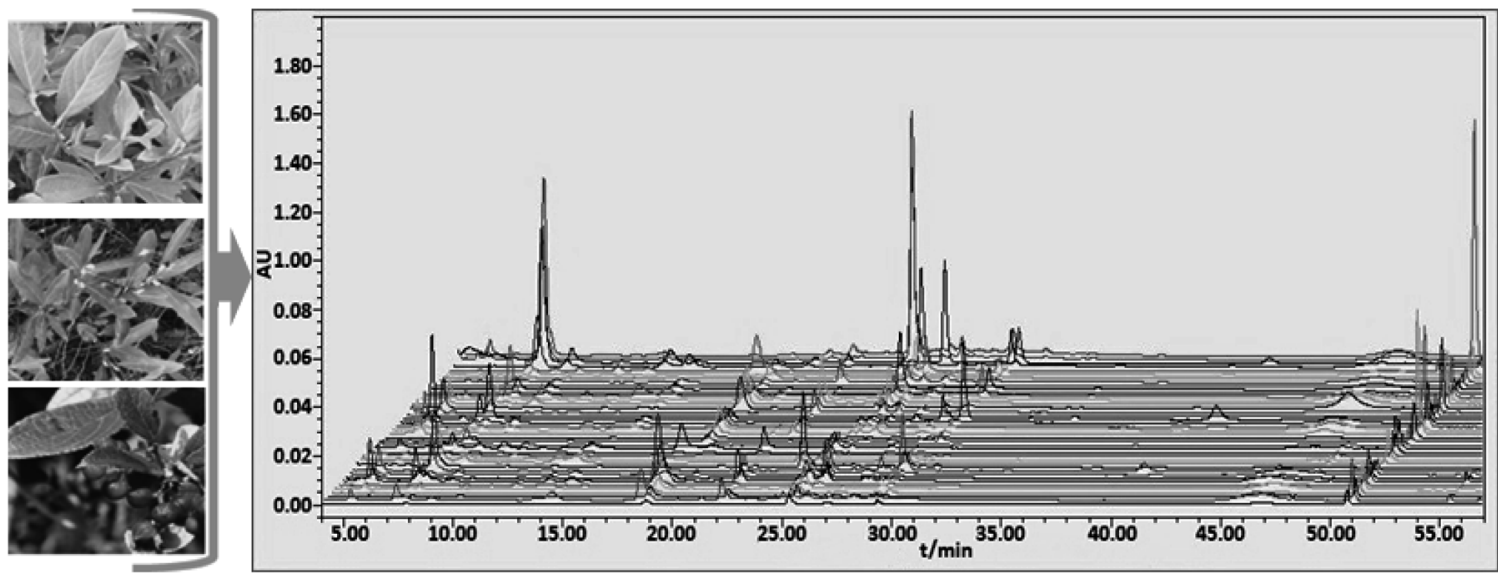

Fig. 2. HPLC Chromatograms of (A) Mixed Standards and (B) 36 Tested Samples

(A) Peak 1 to peak 8 are chlorogenic acid, vanillic acid, MSTG-B, hyperoside, cynaroside, salicylic acid, quercitrin and methyl salicylate, respectively. 
the signal-to-noise ratio $(S / N)$ was $3: 1$ and $10: 1$. The results can be seen in Table 5 .

The precision of the chromatographic method was constituted of intra- and inter-day precision. The mixed standard solutions of three different concentrations were analyzed six times within one day. Repeat this action twice per day for three days, and the RSDs were intra- and inter-day precision, respectively. The precision was based on RSD. Here, the precision RSD values of the retention times and peak areas were less than $2.21 \%$, which demonstrated the good reproducibility of the analytical method (Table 5). To determinate method repeatability, we made an assay, the six different working solutions of the same sample. The RSD value of the retention times was within the range of 0.01 to $0.58 \%$ and that of peak areas was in the range from 2.18 to $3.49 \%$. It illustrated the method had good repeatability. The sample solution was reposited at room temperature to study sample stability in triplicate at $0,2,4,8,12$ and $24 \mathrm{~h}$. The RSD value within the range of 0.36 to $2.19 \%$ revealed that the method was stable. To investigate the accuracy of the method, recovery determination was applied by adding the eight standards into $1.0 \mathrm{~g} \mathrm{G}$. hookeri sample (whole plant), and making their content become approximately 80,100 and $120 \%$ in the sample, respectively. And the spiked samples were extracted and analyzed in triplicate as described above. The test was repeated three times for the calculation of recovery at each added level. The recoveries of all eight compounds were between 97.59 and $105.96 \%$, together with the maximal RSD value of $3.24 \%$ (Table 6). It indicated the analysis method possessing good accuracy. The above results illustrated this analytic method being accurate, sensitive, and stable, which revealed a well accuracy for the determination of the eight analytes.

Statistical Studies In order to investigate whether active

Table 4. Linear Regression of Eight Compounds

\begin{tabular}{clcr}
\hline \hline Compounds & \multicolumn{1}{c}{ Linear regression } & \multicolumn{1}{c}{$R^{2}$} & Range $(\mu \mathrm{g} / \mathrm{mL})$ \\
\hline $\mathbf{1}$ & $y=22904.05 x-41280.91$ & 0.9999 & $1.9-214.1$ \\
$\mathbf{2}$ & $y=19495.91 x-12248.73$ & 0.9998 & $1.9-192.0$ \\
$\mathbf{3}$ & $y=9302.05 x+874.47$ & 0.9997 & $2.33-153.0$ \\
$\mathbf{4}$ & $y=867.46 x-491.27$ & 1 & $12.0-510.0$ \\
$\mathbf{5}$ & $y=9680.34 x+10446.46$ & 0.9999 & $4.1-204.0$ \\
$\mathbf{6}$ & $y=12622.27 x-22341.38$ & 0.9997 & $1.5-250.0$ \\
$\mathbf{7}$ & $y=10271.84 x+1371.84$ & 0.9999 & $1.4-202.0$ \\
$\mathbf{8}$ & $y=9816.20 x-2967.06$ & 0.9998 & $2.0-102.0$ \\
\hline
\end{tabular}

components content was affected by different plant origins or medical parts, a non-parametric method, the Kruskal-Wallis analysis (KWA), was employed. It is the non-parametric analogue of a one-way ANOVA. ${ }^{26}$ ) This method was often applied in the quality control of traditional Chinese medicine (TCM) and used to test the difference between multiple samples with an abnormal distribution. ${ }^{27,28)}$ The KWA result was given in Table 7. Interestingly, the values of $\mathrm{H}$ statistic in plant origins analysis were greater than those in medical parts. The $p$ values of the former $(p<0.05)$ were far less than those of the latter $(p>0.05)$. It meant that the components content had significant differences among various plant origins. The opposite result was present in the medical parts. Particularly, the content of compounds 2, 4, 6 and $\mathbf{8}$ had greatly significant differences $(p<0.01)$ among the eight Gaultheria species. Therefore, they can be considered as the index components more scientifically to control the quality of Gaultheria species. The approximate anti-rheumatism effects $(p>0.05)$ of different medical parts were shown in Table 7. It explained the phenomenon, various medicinal parts used to treat rheumatism by many ethnic minorities.

To further search the resemblances (in some sense or another) and differences among plant origins, another chemometric technique, the hierarchical cluster analysis (HCA) was carried out. HCA is a multivariate analysis technique, and it can divide samples into several groups in light of samples' similarities. It is usually used in the taxonomy of TCM. In this study, it was also applied to classification of 36 Dianbaizhu samples. The content of 8 constituents in 36 samples from various plant species formed a matrix of $36 \times 8$ (Table 2). As Fig. 3 displayed, the quality characteristics of all samples became more clear by using HCA. Upon on the squared Euclidean distance among samples, all 36 samples were classified into two broad categories, clusters I and II. The eight ingredients had different content distribution in the two clusters. It was very interesting that cluster II only contained one species, $G$. leucocarpa var. yunnanensis (batch D). This suggested that its quality may differ from the others'. Combined with the results of KWA, it further revealed that G. leucocarpa var. yunnanensis possessed the highest quality in all tested plant origins. And it is a good explanation for the fact, G. leucocarpa var. yunnanensis being as the dominant plant species in the treatment of rheumatism.

Factor analysis (FA), another multivariate statistical technique, can reduce the data dimensionality and seek for hidden representative factors based on the differences in samples. It

Table 5. Precision, Repeatability, Stability, LOD and LOQ

\begin{tabular}{|c|c|c|c|c|c|c|c|c|c|}
\hline \multirow[b]{2}{*}{ Compounds } & \multicolumn{2}{|c|}{ Intra-day precision $(n=6)$} & \multicolumn{2}{|c|}{ Inter-day precision $(n=3)$} & \multicolumn{2}{|c|}{ Repeatability $(n=6)$} & \multirow{2}{*}{$\begin{array}{c}\text { Stability } \\
\text { RSD of PA } \\
(\%)\end{array}$} & \multirow{2}{*}{$\begin{array}{c}\text { LOD } \\
(\mu \mathrm{g} / \mathrm{mL})\end{array}$} & \multirow{2}{*}{$\begin{array}{c}\text { LOQ } \\
(\mu \mathrm{g} / \mathrm{mL})\end{array}$} \\
\hline & $\begin{array}{c}\mathrm{RSD} \text { of } \mathrm{RT}^{a)} \\
(\%)\end{array}$ & $\begin{array}{c}\mathrm{RSD} \text { of } \mathrm{PA}^{b)} \\
(\%)\end{array}$ & $\begin{array}{l}\text { RSD of RT } \\
(\%)\end{array}$ & $\begin{array}{c}\text { RSD of PA } \\
(\%)\end{array}$ & $\begin{array}{c}\text { RSD of RT } \\
(\%)\end{array}$ & $\begin{array}{c}\text { RSD of PA } \\
(\%)\end{array}$ & & & \\
\hline 1 & 0.10 & 1.13 & 0.21 & 1.43 & 0.58 & 2.52 & 0.99 & 0.56 & 1.75 \\
\hline 2 & 0.09 & 0.63 & 0.12 & 1.08 & 0.33 & 3.49 & 1.92 & 0.31 & 0.98 \\
\hline 3 & 0.07 & 0.95 & 0.31 & 1.11 & 0.46 & 3.26 & 0.72 & 0.83 & 2.61 \\
\hline 4 & 0.12 & 1.81 & 0.16 & 2.21 & 0.07 & 2.26 & 0.71 & 3.21 & 10.70 \\
\hline 5 & 0.14 & 0.78 & 0.32 & 1.34 & 0.08 & 2.81 & 2.19 & 0.30 & 1.04 \\
\hline 6 & 0.20 & 0.71 & 0.25 & 1.71 & 0.06 & 2.97 & 0.36 & 0.42 & 1.41 \\
\hline 7 & 0.18 & 0.80 & 0.21 & 1.31 & 0.04 & 2.90 & 0.76 & 0.36 & 1.20 \\
\hline 8 & 0.08 & 0.53 & 0.12 & 0.94 & 0.01 & 2.18 & 1.02 & 0.21 & 0.62 \\
\hline
\end{tabular}

a) RT: Retention time. b) PA: Peak-area percentage. 
Table 6. Recoveries of the Eight Compounds

\begin{tabular}{|c|c|c|c|c|c|c|}
\hline Compounds & Contained $^{a)}(\mu \mathrm{g})$ & Added $(\mu \mathrm{g})$ & Found $^{b)}(\mu \mathrm{g})$ & Recovery $^{c)}(\%)$ & Mean (\%) & RSD (\%) \\
\hline \multirow[t]{3}{*}{1} & 293.2 & 354.0 & 661.5 & 104.03 & 101.51 & 2.36 \\
\hline & & 290.2 & 581.2 & 99.24 & & \\
\hline & & 226.5 & 522.6 & 101.28 & & \\
\hline \multirow[t]{3}{*}{2} & 48.1 & 58.3 & 106.0 & 99.31 & 98.60 & 2.11 \\
\hline & & 48.1 & 94.4 & 96.25 & & \\
\hline & & 40.4 & 88.6 & 100.24 & & \\
\hline \multirow[t]{3}{*}{3} & 280.2 & 312.0 & 594.5 & 100.74 & 98.90 & 2.47 \\
\hline & & 304.0 & 583.7 & 99.82 & & \\
\hline & & 266.0 & 535.9 & 96.13 & & \\
\hline \multirow[t]{3}{*}{4} & 355.9 & 416.2 & 788.2 & 103.86 & 100.14 & 3.24 \\
\hline & & 357.7 & 705.8 & 97.81 & & \\
\hline & & 285.2 & 637.6 & 98.77 & & \\
\hline \multirow[t]{3}{*}{5} & 86.7 & 104.3 & 199.9 & 108.50 & 105.96 & 2.68 \\
\hline & & 86.4 & 175.6 & 102.89 & & \\
\hline & & 69.3 & 160.5 & 106.49 & & \\
\hline \multirow[t]{3}{*}{6} & 262.8 & 316.5 & 569.2 & 96.80 & 97.59 & 2.58 \\
\hline & & 262.0 & 513.2 & 95.57 & & \\
\hline & & 211.2 & 474.9 & 100.42 & & \\
\hline \multirow[t]{3}{*}{7} & 131.9 & 157.9 & 284.2 & 96.45 & 98.96 & 2.83 \\
\hline & & 130.2 & 260.1 & 98.46 & & \\
\hline & & 105.2 & 239.2 & 101.99 & & \\
\hline \multirow[t]{3}{*}{8} & 2383.8 & 2865.6 & 5217.3 & 98.87 & 101.15 & 2.57 \\
\hline & & 2374.7 & 4773.2 & 100.61 & & \\
\hline & & 1923.1 & 4383.8 & 103.99 & & \\
\hline
\end{tabular}

a) Contained: the actual compound's content of $1.0 \mathrm{~g}$ sample. $b$ ) Found: the amounts of the compound found in the sample after addition of the standard stock solutions. c) Recovery $(\%)=[($ Found - Contained $) /$ Added $] \times 100 \%$.

Table 7. Kruskal-Wallis Analysis of Plant Origins and Medical Parts

\begin{tabular}{cccccc}
\hline \hline \multirow{2}{*}{ Components } & \multicolumn{2}{c}{ Plant origins analysis } & & \multicolumn{2}{c}{ Medical parts analysis } \\
\cline { 2 - 3 } \cline { 5 - 6 } & H Statistic & $p$ Value & & H Statistic & $p$ Value \\
\hline $\mathbf{1}$ & 16.944 & $0.049^{*}$ & & 7.577 & 0.056 \\
$\mathbf{2}$ & 23.846 & $0.005^{* *}$ & & 3.190 & 0.363 \\
$\mathbf{3}$ & 19.293 & $0.023^{*}$ & & 2.116 & 0.549 \\
$\mathbf{4}$ & 23.408 & $0.005^{* *}$ & & 3.918 & 0.270 \\
$\mathbf{5}$ & 18.375 & $0.031^{*}$ & & 6.091 & 0.107 \\
$\mathbf{6}$ & 22.459 & $0.008^{* *}$ & & 1.754 & 0.625 \\
$\mathbf{7}$ & 19.177 & $0.024^{*}$ & & 4.265 & 0.234 \\
$\mathbf{8}$ & 27.016 & $0.001^{* *}$ & & 0.252 & 0.969 \\
\hline
\end{tabular}

$* p<0.05$ and $* * p<0.01$ indicated a statistically significant difference among the distribution of components content.

has been widely applied in the chemometrics research of active ingredients. ${ }^{29-31)}$ In the research on TCM, FA can be used to seek key and representative chemical components from the complex chemical system of Chinese medicine (CM). The factoring types include principal component analysis (PCA), canonical factor analysis (CFA) and others. Here, PCA was employed as the method of FA.

The FA displayed the first two principal factors $(P F 1$ and $P F 2$ ), were chosen as the representative, and they can explained nearly $77 \%$ information of eight active ingredients (Table 8). Moreover, $P F 1$ and $P F 2$ could be used for further quality assessment of Dainbaizhu samples. They could be severally expressed as follow:

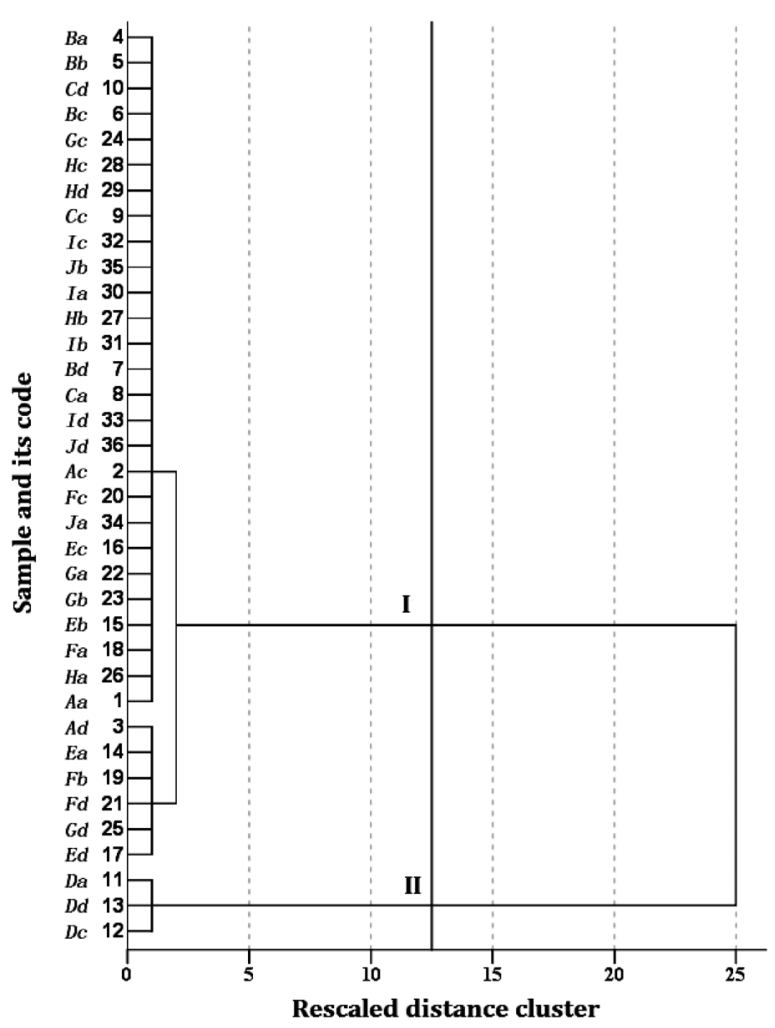

Fig. 3. Dendrogram of Clustering of 36 Samples

The clustering method used Ward linkage and the calculation of sample interval used the squared Euclidean distance. 
Table 8. FA and Data Distribution Analysis Results of the Eight Analytes in 36 Samples

\begin{tabular}{|c|c|c|c|c|c|c|c|c|}
\hline \multirow{2}{*}{ Compounds } & \multirow{2}{*}{ Total } & \multicolumn{2}{|c|}{ Initial eigenvalues $^{a}$ ) } & \multicolumn{2}{|c|}{ Compound matrix } & \multirow{2}{*}{ Mean } & \multicolumn{2}{|c|}{$95 \%$ Confidence interval } \\
\hline & & $\%$ Variance & $\%$ Cumulative & $P F 1$ & $P F 2$ & & Lower limit & Upter limit \\
\hline 1 & 4.75 & 59.36 & 59.36 & 0.959 & -0.087 & 1.58 & 0.37 & 2.78 \\
\hline 2 & 1.40 & 17.51 & 76.87 & 0.917 & 0.140 & 0.06 & 0.02 & 0.10 \\
\hline 3 & 0.76 & 9.53 & 86.41 & 0.176 & -0.837 & 0.07 & 0.02 & 0.11 \\
\hline 4 & 0.62 & 7.73 & 94.14 & 0.891 & 0.249 & 40.71 & 10.49 & 70.93 \\
\hline 5 & 0.27 & 3.43 & 97.56 & 0.500 & 0.552 & 0.48 & 0.17 & 0.79 \\
\hline 6 & 0.13 & 1.66 & 99.23 & 0.950 & 0.113 & 0.37 & 0.15 & 0.58 \\
\hline 7 & 0.03 & 0.42 & 99.65 & 0.934 & 0.145 & 1.14 & 0.23 & 2.05 \\
\hline 8 & 0.03 & 0.35 & 100.00 & -0.372 & 0.522 & 2.17 & 1.42 & 2.92 \\
\hline
\end{tabular}

a) Extraction method: principal component analysis.

Table 9. Rotated Component Score and Component Score Coefficient

\begin{tabular}{|c|c|c|c|c|}
\hline \multirow{2}{*}{ Compounds } & \multicolumn{2}{|c|}{ Rotated component matrix ${ }^{a}$} & \multicolumn{2}{|c|}{$\begin{array}{l}\text { Component score } \\
\text { coefficient matrix }^{b} \text { ) }\end{array}$} \\
\hline & $P F 1$ & $P F 2$ & $P F 1$ & $P F 2$ \\
\hline 1 & 0.917 & 0.293 & 0.184 & 0.105 \\
\hline 2 & 0.925 & 0.063 & 0.210 & -0.055 \\
\hline 3 & -0.011 & 0.855 & -0.094 & 0.591 \\
\hline 4 & 0.816 & 0.437 & 0.144 & 0.215 \\
\hline 5 & 0.608 & -0.430 & 0.188 & -0.362 \\
\hline 6 & 0.952 & 0.096 & 0.213 & -0.035 \\
\hline 7 & 0.943 & 0.062 & 0.214 & -0.058 \\
\hline 8 & -0.250 & -0.590 & 0.005 & -0.381 \\
\hline
\end{tabular}

a) Rotation method: varimax with kaiser normalization. b) Extraction method: principal component analysis. The authors declare no confict of interest.

$$
\begin{aligned}
P F 1= & 0.959 X_{1}+0.917 X_{2}+0.176 X_{3}+0.891 X_{4} \\
& +0.5 X_{5}+0.95 X_{6}+0.934 X_{7}-0.372 X_{8} \\
P F 2= & -0.087 X_{1}+0.14 X_{2}-0.837 X_{3}-0.249 X_{4} \\
& +0.552 X_{5}+0.113 X_{6}+0.145 X_{7}+0.552 X_{8}
\end{aligned}
$$

Rotated component matrix displayed that, $P F 1$ was most correlated with active compounds 1, 2, and 4-7, while $P F 2$ was most correlated with compounds $\mathbf{3}$ and $\mathbf{8}$ (Table 9). The two score variables originated from $P F 1$ and $P F 2$ were representative of the eight compounds' content with only a $23 \%$ loss of the content information (Table 9). The content mean values of eight analytes, together with their lower and the upper limits were given in Table 8. Obviously, there were great deals of differences among the range of those limits. And each lower limit value could be used as the minimal limits to control the quality of Dianbaizhu. The mainstream species, G. leucocarpa var. yunnanensis could be chosen as a reference for the quality evaluation of other Gaultheria species.

The Fig. 4 showed that, eight active constituents were classified into two groups, group I and II. What's most interesting here, the group I only contains two active ingredients (3 and 8) possessing a similar chemical structure with aspirin. For all we know, MSTG-B (3) only isolated from G. leucocarpa var. yunnanensis and Lycopersicon esculentum, exhibited remarkable anti-inflammatory activity. ${ }^{6,32)}$ It states that FA is very effective for the study on bioactive components in TCM. Another group, group II, mainly included organic acids (1, 2 and $\mathbf{6})^{15,33-35)}$ and flavonoids $(4,5 \text { and } 7)^{36-40)}$ which possess good anti-inflammatory activities. The two groups severally

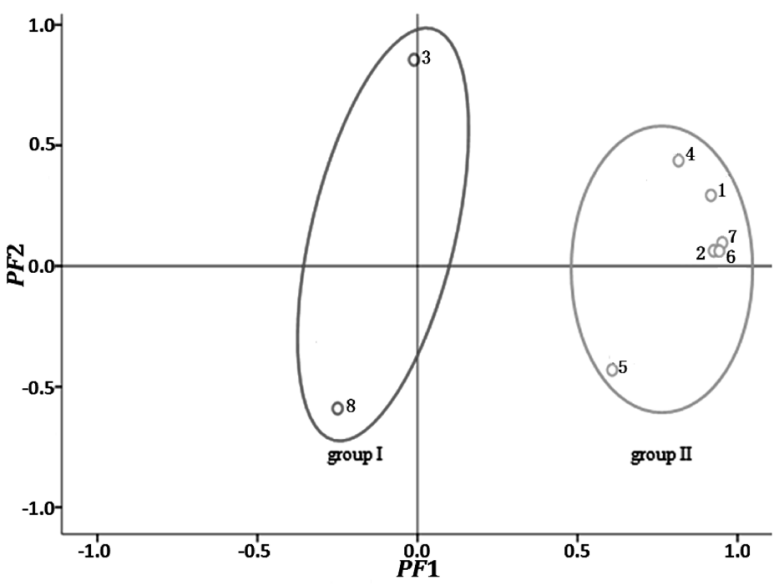

Fig. 4. Factor Plot in Rotated Space of Eight Active Ingredients

Compounds $\mathbf{1}$ to $\mathbf{8}$ are chlorogenic acid, vanillic acid, MSTG-B, hyperoside, cynaroside, salicylic acid, quercitrin and methyl salicylate, respectively.

represented two types of significant index components. Thus, the two types of index components could be considered as the primary representative ingredients of Dianbaizhu. Futhermore, they should be included in the quality control and evaluation of Dianbaizhu.

To compare intuitively the quality of eight Gaultheria species and four officinal parts, the score of $P F 1$ and $P F 2$ in all 36 samples was plotted with $2 \mathrm{D}$ graph (Fig. 5). In the graph, $P F 1$ and $P F 2$ as a whole represented all eight active compounds. Generally, the pharmacological effects of active constituents are in positive correlation with their dose within certain limits. ${ }^{41-43)}$ Accordingly, the score of $P F 1$ and $P F 2$ could reflect the quality of Dianbaizhu in some degrees. The higher factor score was, the better quality was (Fig. 5). Qualitatively, the species 4 (G. leucocarpa var. yunnanensis) was much better than the other tested species. The species 8 (G. fragrantissima) maybe had the worst quality in the eight species. And for the rest of species, they had a similar quality. Additionally, the content distributions of all eight active ingredients had less uniformity in the species than those in the medicinal parts (Fig. 5). This demonstrated that there were great quality differences among Gaultheria species, and the officinal parts had no significant quality differences in view of the compounds content. These inferences were consistent with the results of KWA.

Apart from the statistical analysis above, the Table 2 obviously showed the fact that, among eight active ingredients, 

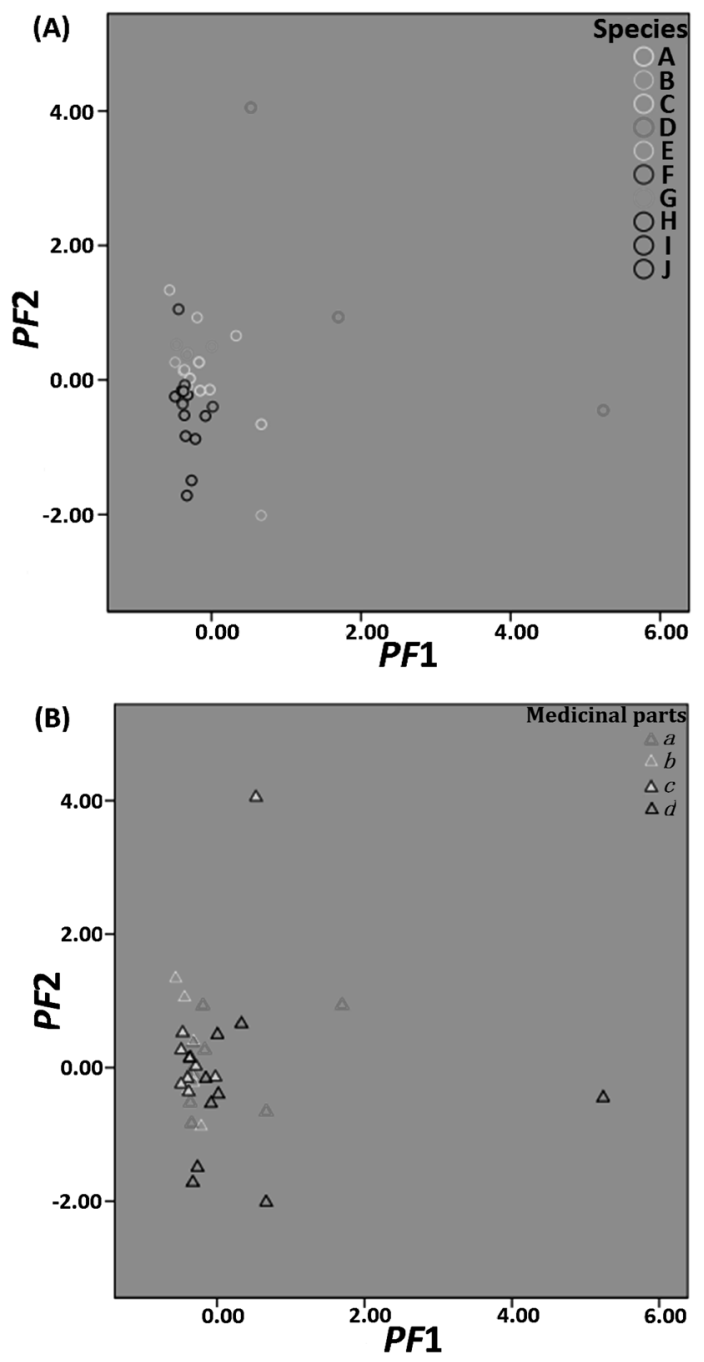

Fig. 5. The 2D Score Plot of (A) 8 Plant Species and (B) 4 Medicinal Parts on $P F 1$ and $P F 2$

(A) Species from A to J are G. trichoclada, G. semi-infera, G. griffithiana, G. leucocarpa var. yunnanensis, G. leucocarpa var. hirsuta, G. hookeri, G. leucocarpa var. pingbienensis and G. fragrantissima, respectively (species $\mathrm{H}$, I and $\mathrm{J}$ are the same). (B) Medicinal parts: $a$ : aerial parts, $b$ : whole plant, $c$ : leaf, $d$ : branch.

both salicylic acid (6) and methyl salicylate (8) existed in about $92 \%$ of samples. Maybe it is because some injurious insects and pathogen infections cause accumulation of salicylic acid (6) and synthesis of volatile methyl salicylate (8) in Dianbaizhu. ${ }^{44-46)}$ And then, salicylic acid (6) as a messenger transfers to other parts of plant via vascular system, resulting in increased systemic resistance to encroachment. ${ }^{47)}$ Analogously, methyl salicylate (8) as airborne messenger floats to other parts of the plant and neighboring plants and enhanced the ability to resist external invasion. ${ }^{47)}$

\section{Conclusion}

A quality evaluation procedure of Dianbaizhu was successfully established using one distinctive ingredient MSTG-B and seven principal ingredients as reference compounds. The optimized procedure based on the eight active constituents was accurate, reliable and comprehensive. It is very suitable for the quality control of several Gaultheria species.

From multivariate statistical results of KWA, HCA and FA, we found that species origins had a significant effect on the
Dianbaizhu quality, while the medicinal parts' did not exhibit. In addition to Gaultheria species origins and medicinal parts as well as their growing environment may also affect the quality of medicinal material. Among eight species, G. leucocarpa var. yunnanensis is not only the uppermost plant species, but also the best one for the treatment of rheumatic diseases according to the comprehensive analysis.

Acknowledgments Financial support of this work was provided by National Natural Science Foundation of China (No. 81001697), Beijing Nova Program (No. 2011070), Selfselected Topic of Beijing University of Chinese Medicine (No. 2011JYB22XS-061), Excellent Talents of Beijing (No. 2012B009999000003), National Training Programs of Innovation and Entrepreneurship for Undergraduates (Nos. 201210026051, 201410026040), and Scientific Research Project of Beijing Educational Committee for Undergraduates (Nos. BJGJ1114, BJGJ1115).

\section{References}

1) Liu W. R., Qiao W. L., Liu Z. Z., Wang X. H., Jiang R., Li S. Y., Shi R. B., She G. M., Molecules, 18, 12071-12108 (2013).

2) Ma X. J., Zhao L., Du C. F., Shi B. Y., Zheng J. H., Chen X. Z., Zhongcaoyao, 32, 945-949 (2001).

3) Ma X. J., Zheng J. H., Chen X. Z., Zhongguo Zhong Yao Za Zhi, 26, 85-89 (2001).

4) Jia M. R., Li X. W., "Chinese National Medicine Records," China Medical Science Press, Beijing, 2005.

5) She G. M., Li D. C., Zhang Y., Guo Z. Q., Lv H. N., She D. M., Beijing Zhongyiyao Daxue Xuebao, 33, 62-72 (2010).

6) Zhang B., Li J. B., Zhang D. M., Ding Y., Du G. H., Biol. Pharm. Bull., 30, 465-469 (2007).

7) Zhang D., Liu R., Sun L., Huang C., Wang C., Zhang D. M., Zhang T. T., Du G. H., Molecules, 16, 3875-3884 (2011).

8) Blacklock C. J., Lawrence J. R., Wiles D., Malcolm E. A., Gibson I. H., Kelly C. J., Paterson J. R., J. Clin. Pathol., 54, 553-555 (2001).

9) Lee S. J., Son K. H., Chang H. W., Do J. C., Jung K. Y., Kang S. S., Kim H. P., Arch. Pharm. Res., 16, 25-28 (1993).

10) Kao E. S., Wang C. J., Lin W. L., Yin Y. F., Wang C. P., Tseng T. H., J. Agric. Food Chem., 53, 430-436 (2005).

11) Kim S.-J., Um J.-Y., Hong S.-H., Lee J.-Y., Am. J. Chin. Med., 39, 171-181 (2011).

12) Zhu X., Zhang H., Lo R., J. Agric. Food Chem., 52, 7272-7278 (2004).

13) dos Santos M. D., Almeida M. C., Lopes N. P., de Souza G. E. P., Biol. Pharm. Bull., 29, 2236-2240 (2006).

14) El-Medany A. M., Bassiouni Y. A., Khattab M. M., Mahesar A. A., Clin. Ther., 35, e98 (2013).

15) Kim M. C., Kim S. J., Kim D. S., Jeon Y. D., Park S. J., Lee H. S., Um J. Y., Hong S. H., Immunopharmacol. Immunotoxicol., 33, 525-532 (2011).

16) Wu Q., Ye C., Han W., Song P. L., Zou H. Y., J. Henan Univ. Med. Sci., 26, 32-33 (2007).

17) Liu S. H., Liang G. P., Qi Z. Z., Wang S. Q., Anhui Nongye Kexue, 39, 18498-18500 (2011).

18) Song Z. Z., Liu Y., Zhongguo Shiyan Fangjixue Zazhi, 18, 99-101 (2012).

19) Liang G. P., Wang S. Q., J. Guiyang College Trad. Chin. Med., 35, $12-16(2013)$.

20) Zhou X. X., Wei Y. J., Hebei Shifan Daxue Xuebao, Ziran Kexueban, 37, 17 (2013).

21) Zhang Z. Z., Guo D. A., Li C. L., Zheng J. H., Koike K., Jia Z. H., Nikaido T., Fan G. Q., Zhongguo Zhong Yao Za Zhi, 24, 164-165 (1999). 
22) Ma X. J., Zhao L., Zhao Y. J., Du C. F., Zheng J. H., Chen X. Z., Zhongcaoyao, 33, 353-354 (2002).

23) Ma X. J., Zhao L., Zhao Y. J., Du C. F., Zheng J. H., Chen X. Z., Zhongguo Zhong Yao Za Zhi, 27, 25-27 (2002).

24) Wu Z. Y., "Flora Yunnanica," Tomus 4, Science Press, Beijing, 1986.

25) Xu S. Y., Modernization of Traditional Chinese Medicine and Materia Medica-WORLD SCIENCE AND TECHNOLOGY, 8, 73-78 (2006).

26) McDonald J. H., "Handbook of Biological Statistics," 2nd ed., Sparky House Publishing, Baltimore, 2009.

27) Lee E. T., Desu M. M., Comput. Meth. Prog. Biol., 2, 315-321 (1972).

28) Chan Y., Walmsley R. P., Phys. Ther., 77, 1755-1762 (1997).

29) Rozett R. W., Petersen E. M., Anal. Chem., 48, 817-825 (1976).

30) Flores M., Grimm C. C., Toldrá F., Spanier A. M., J. Agric. Food Chem., 45, 2178-2186 (1997).

31) Armey M. F., Fresco D. M., Moore M. T., Mennin D. S., Turk C. L., Heimberg R. G., Kecmanovic J., Alloy L. B., Assessment, 16, 315-327 (2009)

32) Ono M., Shiono Y., Tanaka T., Masuoka C., Yasuda S., Ikeda T., Okawa M., Kinjo J., Yoshimitsu H., Nohara T., J. Nat. Med., 64, 500-505 (2010).

33) Gu Y. D., Xia Y., "Chemical Dictionary," Shanghai Dictionary Press, Shanghai, 1989.

34) Bonita J. S., Mandarano M., Shuta D., Vinson J., Pharmacol. Res., 55, 187-198 (2007).
35) Stanely Mainzen Prince P., Rajakumar S., Dhanasekar K., Eur. J. Pharmacol., 668, 233-240 (2011).

36) Bruneton J., "Pharmacognosy, Phytochemistiy, Medicinal Plants," USA Lavoisier Publishing Inc., New York, 1995.

37) Lu J., Feng X., Sun Q., Lu H., Manabe M., Sugahara K., Ma D., Sagara Y., Kodama H., Clin. Chim. Acta, 316, 95-99 (2002).

38) Rotelli A. E., Guardia T., Juarez A. O., De la Rocha N. E., Pelzer L. E., Pharmacol. Res., 48, 601-606 (2003).

39) Camuesco D., Comalada M., Rodríguez-Cabezas M. E., Nieto A. Lorente M. D., Concha A., Zarzuelo A., Gálvez J., Br. J. Pharmacol., 143, 908-918 (2004).

40) Comalada M., Camuesco D., Sierra S., Ballester I., Xaus J., Gálvez J., Zarzuelo A., Eur. J. Immunol., 35, 584-592 (2005).

41) Crevoisier C., Ziegler W. H., Eckert M., Heizmann P., Br. J. Clin. Pharmacol., 16 (Suppl. 1), 51S-61S (1983).

42) Chou T. C., Talalay P., Adv. Enzyme Regul., 22, $27-55$ (1984).

43) Leoncini M., Toso A., Maioli M., Tropeano F., Villani S., Bellandi F., J. Am. Coll. Cardiol., 63, 71-79 (2014).

44) Reymond P., Weber H., Damond M., Farmer E. E., Plant Cell, 12, 707-720 (2000).

45) Mallinger R. E., Hogg D. B., Gratton C., J. Econ. Entomol., 104, 115-124 (2011).

46) Lincoln T., Eduardo Z., "Plant Physiology," 3rd ed., Sinauer Associates, Sunderland, 2002, p. 306

47) Shulaev V., Silverman P., Raskin I., Nature (London), 385, 718-721 (1997). 